\title{
Pseudolaric Acid B Inhibits Proliferation, Invasion, and Angiogenesis in Esophageal Squamous Cell Carcinoma Through Regulating CDI47
}

This article was published in the following Dove Press journal: Drug Design, Development and Therapy

\section{Zhe Yin* \\ Huarong Cai* \\ Zhiqiang Wang \\ Yuequan Jiang}

Department of Thoracic Surgery, Chongqing University Cancer Hospital, Chongqing 400030, China

*These authors contributed equally to this work
Correspondence: Yuequan Jiang Department of Thoracic Surgery, Chongqing University Cancer Hospital, No. 18I, Hanyu Road, Shapingba District, Chongqing 400030, China

Tel +86-023-65075660

Email yuequanjij@।63.com
Background: Esophageal squamous cell carcinoma (ESCC) is a common malignant tumor of the digestive system. Studies have shown that pseudolaric acid B (PAB) has several pharmacological effects like anti-microtubule, anti-angiogenesis, and antitumor functions, while the effect and mechanism of PAB on esophageal cancer are still unclear. This study was designed to investigate the effects of PAB on ESCC.

Methods: To study the effects of PAB on the biological function through a series of in vitro and in vivo experiments.

Results: The results revealed that $\mathrm{PAB}$ inhibited the proliferation, invasion, and migration, but promoted the apoptosis of ESCC. Moreover, PAB restrained the growth of cancer cells in vivo and inhibited the angiogenesis of HUVEC in mice with ESCC. CD147 expression was increased in the esophageal squamous cell lines, and interference with CD147 hindered the proliferation, invasion, and migration of ESCC cells, and inhibited the growth and angiogenesis of the esophageal squamous cell line. PAB reduced the expression of CD147 in vivo and in vitro. The expression of MMP2, 3, and 9 was increased after overexpression of $\mathrm{CD} 147$, which provided the opportunity to reverse the role of PAB in inhibiting proliferation, invasion, migration, and angiogenesis of ESCC.

Discussion: The results revealed that PAB inhibited the proliferation, invasion, migration, and angiogenesis of ESCC in vitro and in vivo by CD147. PAB is a promising monomer for therapy of ESCC, providing references for future research on ESCC treatment.

Keywords: esophageal squamous cell carcinoma, pseudolaric acid B, CD147, angiogenesis

\section{Introduction}

Esophageal cancer is one of the most common malignant tumors that seriously endanger human's life and health. ${ }^{1}$ Esophageal cancer mainly includes esophageal squamous cell carcinoma (ESCC) and esophageal adenocarcinoma exhibiting two kinds of pathological types. ${ }^{2}$ At present, the pathogenesis of ESCC is not fully understood. Due to the insidious onset of ESCC, the patients are mostly diagnosed in the progressive stage. Even through there are comprehensive treatment options such as surgery, radiotherapy, and chemotherapy, the 5-year survival rate is only $15-25 \%{ }^{3,4}$ In this process, the monomeric compounds of traditional Chinese medicine (TCM) play an important role in the antitumor toxicity reduction and synergism. ${ }^{5}$ Therefore, it is of great significance to searching for a new drug that can block tumor metastasis with clear molecular targets, which has also become the focus in ESCC research. 
Pseudolaric acid B (PAB), extracted from the golden larch root and the trunk of diterpenoid acids, has a long history and is a kind of clinically applied TCM extract, with many biological activities, including antifungal, antifertility, cytotoxicity, antibacterial microtubule protein, antitumor, and anti-angiogenesis activities. ${ }^{6-8}$ Previous studies have also shown that $\mathrm{PAB}$ induces growth inhibition in different types of cancer via cell cycle arrest and apoptosis induction, such as ovarian cancer, lung cancer, prostate cancer, and leukemia. ${ }^{9,10}$ PAB has considerable cytotoxicity against several cancer cell lines in the brain, colon, lung, breast, and kidney. ${ }^{11,12}$ In the study of early pregnancy termination induced by artificial embryonic stem cells, researchers found that artificial embryonic stem cells may have anti-angiogenic effects. ${ }^{13}$ Other studies have demonstrated that PAB can inhibit HUVEC proliferation and downregulate the expression of VEGF and HIF $1 \alpha .^{14,15}$ Therefore, the first part of this paper aims to explore the role of $\mathrm{PAB}$ in ESCC and its effect on the angiogenesis.

Recent studies have elucidated that PAB can directly target CD147, thus playing an anticancer role. ${ }^{16} \mathrm{CD} 147$ is found on the surface of lung cancer cell lines and can induce the synthesis of MMP family proteins. ${ }^{17} \mathrm{~A}$ large number of studies have shown that overexpression of CD147 can promote the development of colon cancer, liver cancer, and other cancer types, ${ }^{18,19}$ and CD147 can inhibit the angiogenesis of lung cancer by inhibiting the expression of VEGF. $^{20}$ Interestingly, previous studies have attested that expression of CD147 is increased in patients with ESCC, and it is related to the basic clinical characteristics. ${ }^{21-23}$ However, the specific study of CD147 in ESCC is still unknown. Therefore, this paper also aims to explore the expression of CD147, probe its role in biological activity and angiogenesis, and investigate whether it involves the modulation of the invasion, migration, and angiogenesis by PAB in ESCC cells.

\section{Materials and Methods \\ Cell Culture and Reagents}

Human TE-1, ECA-109, KYSE410, and KYSE520 cells of ESCC were incubated in RPMI-1640 medium (Hyclone, USA) with $10 \%$ fetal bovine serum (Gibco, USA) and $2 \mathrm{~mL}-$ glutamine, $100 \mathrm{U} / \mathrm{mL}$ penicillin, and streptomycin at $37^{\circ} \mathrm{C}$ within a humidified atmosphere of $5 \% \mathrm{CO}_{2}$. $\mathrm{PAB}$ were purchased from the National Institute for the Control of Pharmaceutical and Biological Products (Beijing, China). The ESCC cells of experimental groups were treated with various concentrations of $\mathrm{PAB}(0.5,2,5$, and $10 \mu \mathrm{M})$ for 24 ,
48, and 72 hours. The cells were incubated in the absence of $\mathrm{PAB}$ as the control group.

\section{Cell Transfection}

Short hairpin RNA (shRNA) for CD147 gene (shRNA-CD147 -1 and shRNA-CD147-2), appropriate negative control (sh$\mathrm{NC}$ ), Overexpression-CD147, and Overexpression-NC were transfected into TE-1 cells when the cells reached 70-80\% confluence. Transfection was carried out using Lipofectamine 2000 (Invitrogen, Carlsbad, CA, USA), according to the manufacturer's instruction. The cells were cultured for 24-72 hours at $37^{\circ} \mathrm{C}$ following transfection. The transfection efficiency of shRNA-CD147-1/2 and Overexpression-CD147 was detected by Western blot and RT-qPCR.

\section{Cell Counting Kit-8 (CCK-8) Assay}

After human TE-1, ECA-109, KYSE410, and KYSE520 cells were treated with $\mathrm{PAB}$ at various concentrations, cells were seeded in 96-well plates at a density of $1 \times 10^{3}$ cells $/ \mathrm{mL}$ and incubated at 24,48 , and 72 hours. Subsequently, $10 \mu \mathrm{L}$ CCK-8 reagent (Roche Diagnostics, Basel, Switzerland) was added into each single well. Following 1 hour of incubation, the absorbance of CCK-8 was measured by an automated plate reader at $490 \mathrm{~nm}$ (Bio-Rad, Hercules, CA, USA).

\section{Wound Healing and Transwell Assays}

The TE-1 cells were plated in 6-well microplates and cultured at $37^{\circ} \mathrm{C}$ until a single cell distribution formed. A sterile plastic pipette tip was used to produce a double-sided wound in cell monolayer. Then, cells were cultured in serum-free RPMI-1640 for 24 hours. Cell gaps were observed under an inverted microscope and images of the wound sites were captured at specific time points. The migratory ability was quantified by measuring the total number of cells in the scratched regions. After 48 hours transfection, the upper chamber was immersed with serum-free RPMI-1640, while RPMI-1640 medium containing 10\% FBS was added to the lower chamber. After incubation for 24 hours, the nonmigrated cells in the upper inserts were removed by a cottontipped swab. The migrated cells were stained with crystal violet. Image-Pro Plus 6.0 was applied to count the number of cell migration and invasion.

\section{Flow Cytometry}

The cell apoptosis was conducted using an Annexin V-fluorescein isothiocyanate (FITC)/propidium iodide (PI) cell apoptosis kit (KeyGen, Nanjing, Jiangsu, China). Briefly, cells in each group were sorted onto 6-well plates at the density 
of $2 \times 10^{6}$ cells per well, after which they were stained with the mixture of $5 \mu \mathrm{L}$ Alexa Flour 488 AnnexinV-FITC and $1 \mu \mathrm{L}$ PI $(100 \mathrm{mg} / \mathrm{mL})$, followed by incubation at room temperature in the dark for 15 minutes. Next, each well of cells were treated with $400 \mu \mathrm{L}$ 1xAnnexin binding buffer and then the cell apoptosis was detected using a flow cytometer. Approximately $1 \times 10^{4}$ cells were included and the percentage of Annexin V+ (apoptotic) cells in each group was evaluated.

\section{Animal Experiments}

The animal experiments were performed in accordance with China Animal Protection Law, and the protocols were approved by the Animal Care and Use Committee of the Chongqing University Cancer Hospital. Female BALB/c mice (nu/nu; 4 weeks old, 18-22 g weight) were purchased from the Shanghai SLAC Animal Center (Shanghai, China). All animals were housed in temperature-controlled cages (temperature $20-25^{\circ} \mathrm{C}$, humidity $20-30 \%$ ) with free access to water and food. All animals received the human care and experimental procedures. All experimental operations were approved by the Ministry of Health of the People's Republic of China (documentation number 19890503). Measures were taken to minimize animal suffering and the animal work took place in the animal laboratory of Chongqing University Cancer Hospital. The mice were quickly asphyxiated to sacrifice after excess ingestion of isoflurane. Then 10,20 , or $30 \mathrm{mg} /$ $\mathrm{kg}$ of PAB was injected into thw abdominal cavity to establish the subcutaneously transplanted tumor animal model.

\section{Western Blot Analysis}

ESCC cells were collected and total proteins were harvested using RIPA lysis buffer (Beyotime Institute of Biotechnology). The protein concentration was then determined using the BCA method (Beyotime Institute of Biotechnology). The protein (30 grams/lane) was isolated by SDS-page gel at $10 \%$ and then transferred to PVDF membrane. After being sealed with 5\% milk at room temperature for 2 hours, primary antibodies were incubated overnight at $4^{\circ} \mathrm{C}$. The membrane was then incubated with the corresponding horseradish peroxidase (HRP)-labeled secondary antibody at room temperature for 2 hours, and the protein expression was detected using ECL detection reagent (EDM Millipore).

\section{Quantitative Reverse Transcription Polymerase Chain Reaction (qRT-PCR)}

Total RNA samples were thawed on ice. Reverse transcription was performed according to the instructions of the PrimeScript RT reagent (TaKaRa, Otsu, Shiga, Japan). The reverse transcription was conducted at $42^{\circ} \mathrm{C}$ for 30 minutes. qRT-PCR was performed using the SYBR Green Master Mix I (TaKaRa) on the ABI 7900 Fast Real-Time PCR System (ABI, Foster City, CA, USA). The reaction conditions were set as follows: Initial denaturation at $95^{\circ} \mathrm{C}$ for 5 minutes. Amplification of 45 cycle consists of three steps: a denaturation step at $95^{\circ} \mathrm{C}$ for 30 seconds, an annealing step at $60^{\circ} \mathrm{C}$ for 30 seconds, and a final extension of 10 minutes at $72^{\circ} \mathrm{C}$. GAPDH was used as the housekeeping gene and relative quantification was performed using the $2^{-\Delta \Delta C T}$ method.

\section{Statistical Analysis}

The experimental data were expressed as the mean \pm standard and were analyzed with SPSS v11.5 (SPSS Inc., Chicago, IL, USA). A one-way ANOVA followed by a Tukey's or Dunnett's test was performed using GraphPad Prism 5 software (GraphPad Software, Inc.) to determine statistical comparisons between groups. A value of $P$ less than 0.05 was considered to indicate a statistically significant difference.

\section{Results}

\section{PAB Inhibited the Proliferation and Invasion Abilities of ESCC Cells in vitro}

The inhibition ratio of ESCC cells (TE-1, ECA-109, KYSE410, and KYSE520) was markedly enhanced with the increasing of PAB dose and treatment time (Figure 1A-D), demonstrating that $\mathrm{PAB}$ played a negative role in cell activity of ESCC cells. Downregulation of the proliferation-related protein (Ki67) and vascular endothelial growth factor A (VEGFA) observed by Western blot also demonstrated that PAB hindered cell proliferation (Figure 1I). Then, as shown in Figure 1E-H, wound healing and transwell assays assessed the migration and invasion of TE- 1 cells. The PAB group presented less migrative and invasive cells compared with the control group, as evaluated by transwell assay and wound healing assay. In addition, PAB reduced the expression of matrix metalloproteinase-2, -3 , and -9 (MMP2, MMP3, and MMP9), indicating the potential mechanism of PAB by modulating cell migration and invasion.

\section{PAB Induced Cell Apoptosis in ESCC Cells}

To analyze the mechanism under the significant inhibition effect of PAB on ESCC cells, the apoptosis was analyzed by flow cytometry with annexin V-FITC staining. The results 

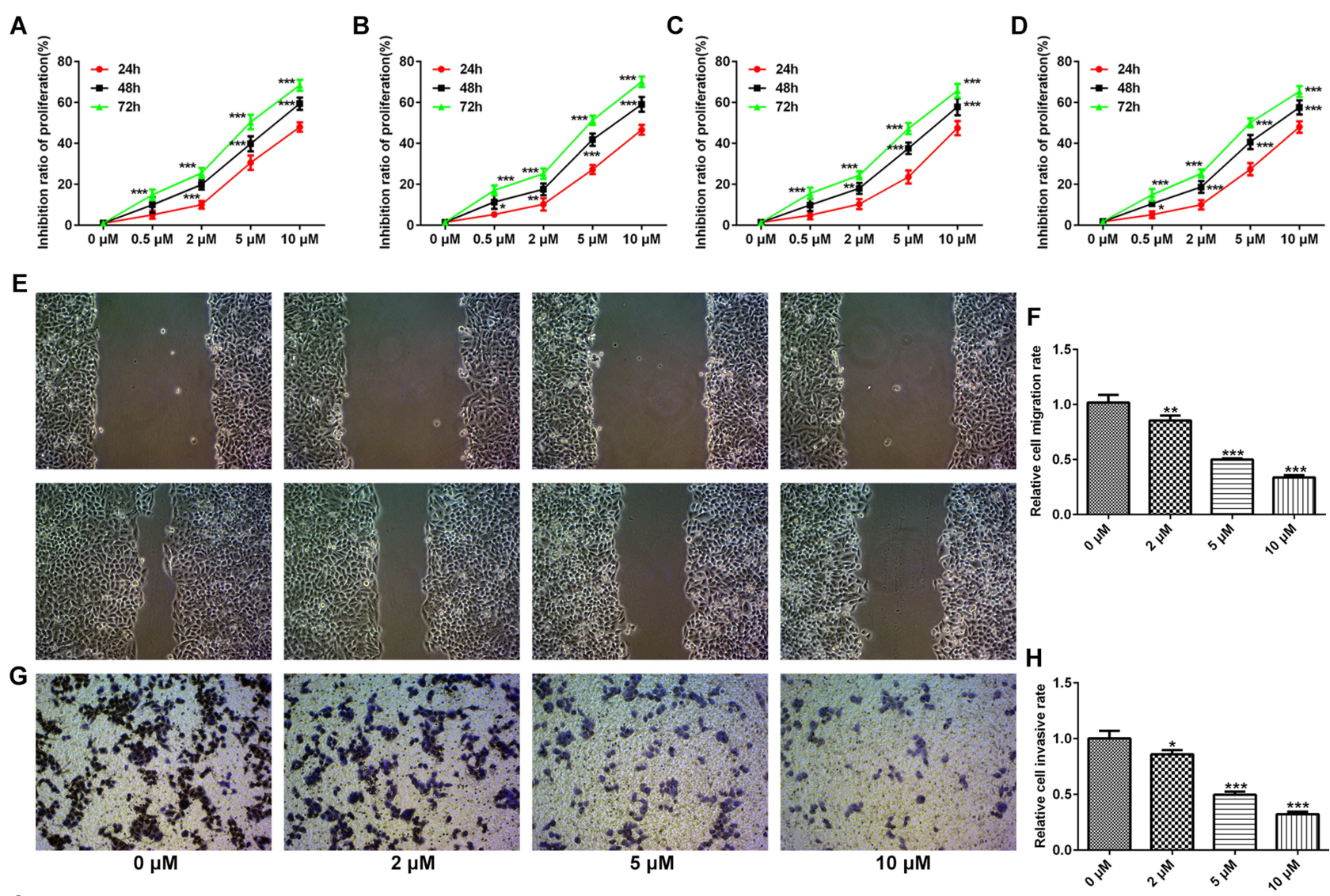

I
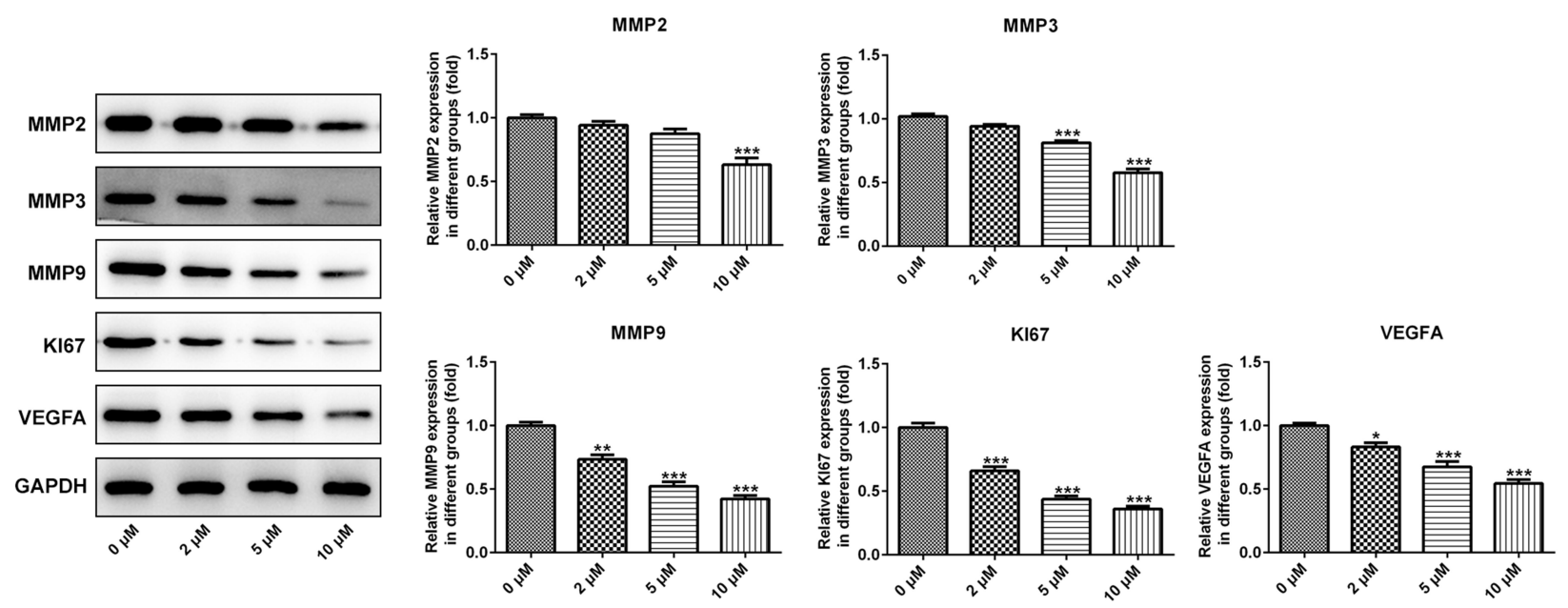

Figure I PAB inhibited the proliferation and invasion ability of ESCC cells in vitro. The inhibition ratio of ESCC cells TE-I (A), ECA- 109 (B), KYSE4I0 (C), and KYSE520 (D) was markedly improved with the increasing of dose and treatment time of PAB. (E-H) Wound healing and transwell assays were used to assess the migration and invasion in TE-I cells. (I) PAB reduced the expression of matrix metalloproteinase-2, -3 , and -9 (MMP2, MMP3, and MMP9), proliferation-related protein (Ki67), and vascular endothelial growth factor $A$ (VEGF A). $* P<0.05, * * P<0.01$, $* * * P<0.001$ vs $0 \mu \mathrm{M}$.

showed that PAB could induce ESCC cell apoptosis (Figure 2A). Furthermore, the results of Western blot showed that $\mathrm{PAB}$ could significantly downregulate $\mathrm{Bcl}-2$ protein expression and upregulate Bax, Cleaved caspase-3, and -9 expression (Figure 2B). The results were consistent with those of flow cytometry.

\section{Efficacy of PAB in Xenograft Experiments in vivo}

To further determine the role of PAB in vivo, an ESCCbearing nude mice model was established and then treated with PAB. In the PAB mice model, PAB injection inhibited the tumor proliferation and resulted in smaller tumor size. 
A
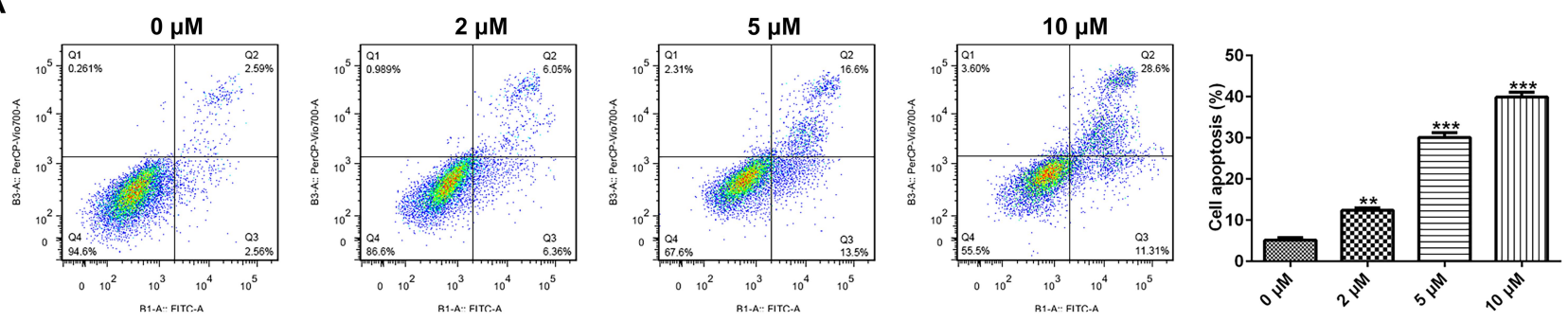

B
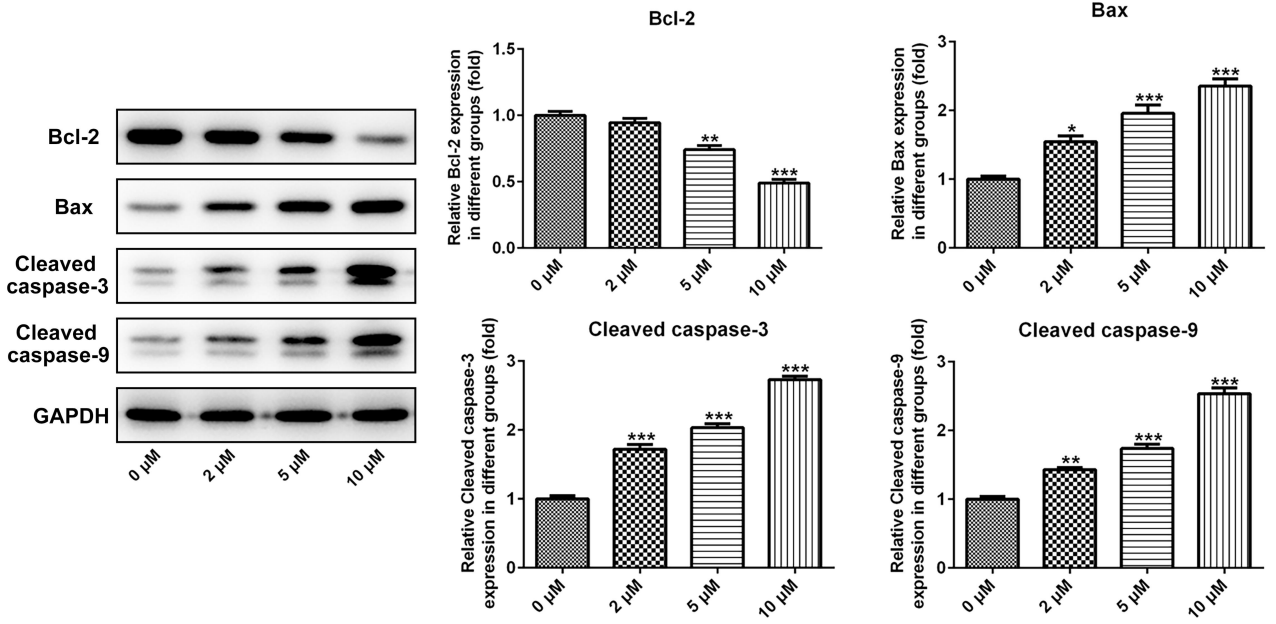

Figure 2 PAB induced cell apoptosis in ESCC cells. (A) The percentages of cell apoptosis were analyzed by flow cytometry with annexin V-FITC staining. (B) Western blotting analysis was performed to investigate the expression of apoptosis-related proteins. $* P<0.05, * * P<0.01$, $* * * P<0.001$ vs $0 \mu \mathrm{M}$.

Moreover, administration of PAB substantially hampered tumor expansion at later time points, causing significant reduction in final tumor volume (Figure $3 \mathrm{~A}$ and $\mathrm{B}$ ) and weight (Figure $3 \mathrm{C}$ and $\mathrm{D}$ ), compared with the control group. The MMP2, MMP3, MMP9, Ki67, CD43, and VEGFA protein expression was also down-regulated (Figure 3E), which indicated that $\mathrm{PAB}$ repressed the growth of ESCC-bearing mice.

\section{PAB Suppressed the Angiogenesis of HUVEC}

We further investigated the effect of PAB on tumor angiogenesis in vivo, medium $(\mathrm{CM})$ with various concentrations of PABs $(0.5,2,5$, and $10 \mu \mathrm{M})$ was added to HUVEC cells and cultured for 24 hours. The results displayed that $\mathrm{PAB}$ inhibited HUVEC angiogenesis (Figure 4A). Furthermore, a Transwell chamber was used to observe the migration ability of HUVEC by PAB. The analysis of the results showed that, compared with the control group, HUVEC in the filtration membrane of the experimental group was reduced, suggesting that $\mathrm{PAB}$ had the ability to inhibit the migration of endothelial cells (Figure 4C). VEGF plays a critical role in endothelial cells. We next determined the effect of PAB on VEGFA expression and found that $\mathrm{PAB}$ treatment markedly decreased the protein expression of VEGF and VEGFR in HUVEC cells in a dose-dependent manner (Figure 4B).

\section{The Role of CDI47 in ESCC}

The latest study showed that $\mathrm{PAB}$ can directly target CD147 to play its anticancer role by using chemical proteomics. It was viewed that the protein and mRNA expression of CD147 was significantly increased in ESCC cells relative to HEEC cells. And the highest levels of CD147 were observed in TE-1 cells (Figure 5A). Then, the interfering plasmid of CD147 was constructed, and the interfering effect was detected by qRT-PCR and Western blot (Figure 5B). Knocking down CD147 in TE-1 cells suppressed cell growth rate (Figure 5C). In addition, transwell assays further confirmed that CD147 knockdown impeded TE-1 cells migration and invasion (Figure 5D-G). Western blot also indicated that Ki67, VEGFA, MMP2, MMP3, and MMP9 expression was decreased in CD147 knockdown cells, hinting the potential mechanism of CD147 by modulation of cell migration and invasion (Figure 5H). 
A

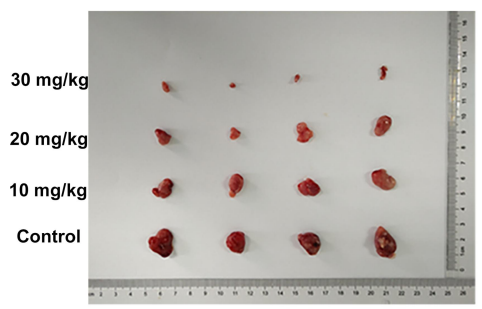

E

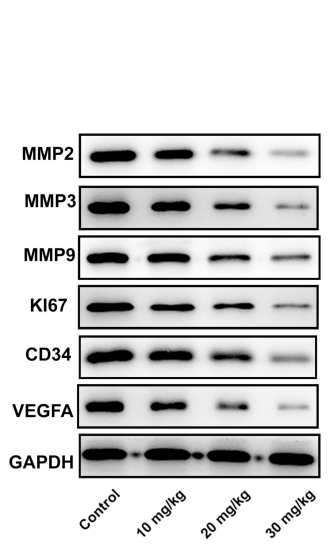

B

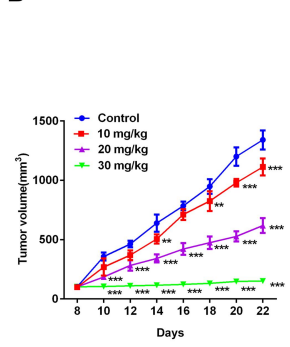

C

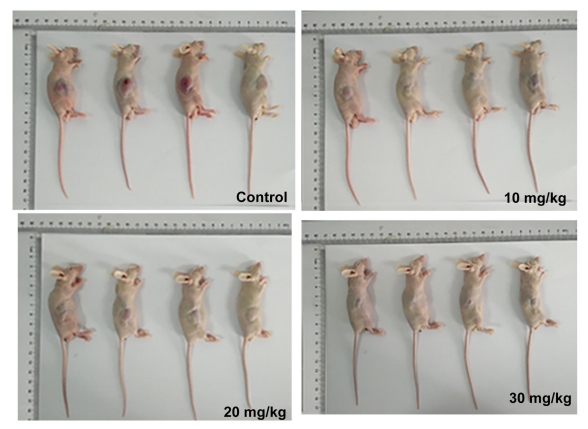

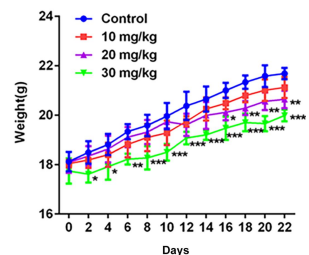

Days

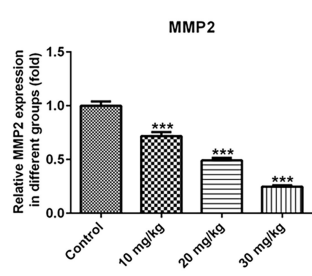

KI67

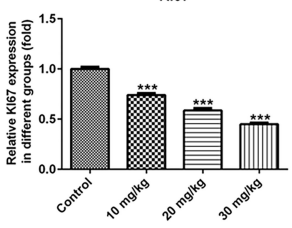

MMP3

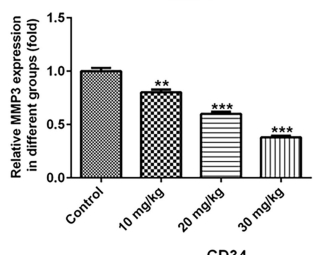

CD34

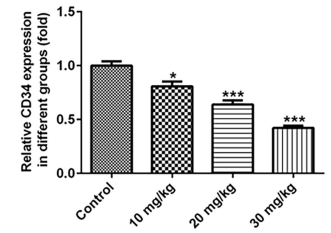

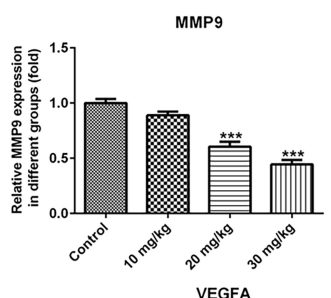

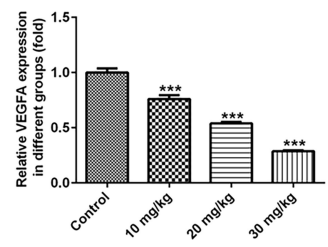

Figure 3 The anticancer role of $P A B$ in vivo. Administration of $P A B$ substantially decreased tumor expansion at later time points, resulting in marked reduction in final tumor volume (A-B) and weight (C-D) compared with control group. (E) Western blotting analysis was performed to investigate the protein expression of MMP2, MMP3, MMP9, Ki67, CD43, and VEGFA. $* P<0.05, * * P<0.01$, $* * * P<0.001$ vs control.

A

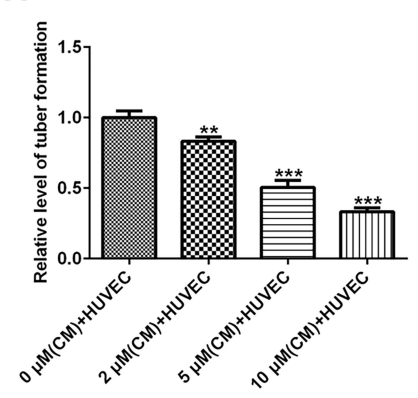

B

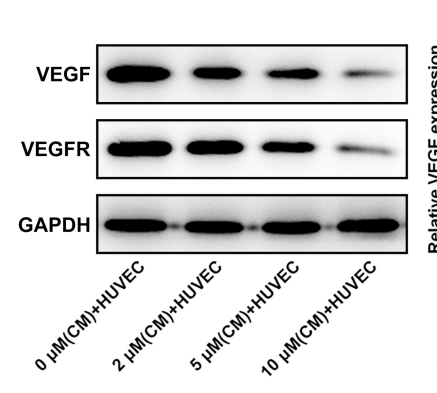

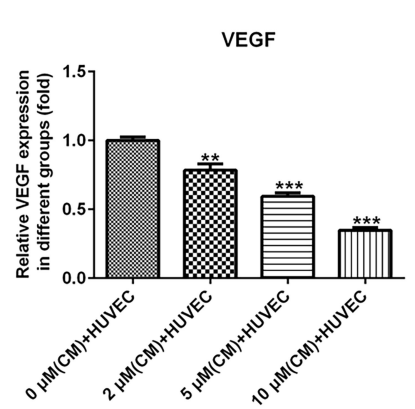

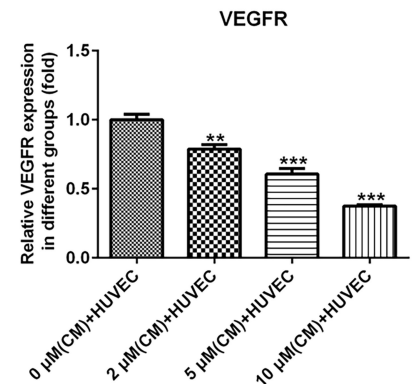

C
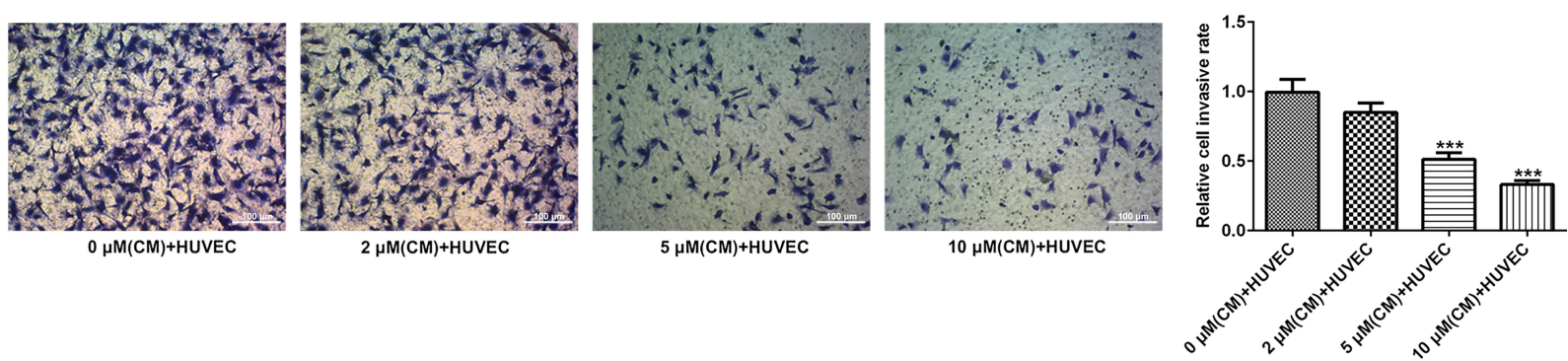

Figure 4 PAB inhibited the angiogenesis of HUVEC. (A) Medium (CM) with partial concentration of PAB $(0.5,2,5$, and $10 \mu M)$ was added to HUVEC cells and cultured for 24 hours. (B) Various concentrations of PAB markedly decreased the protein expression of VEGF and VEGFR in HUVEC cells. (C) Transwell chamber was used to observe the migration ability of HUVEC by PAB. $* * P<0.01$, $* * * P<0.001$ vs $0 \mu M(C M)+H U V E C$. 
A

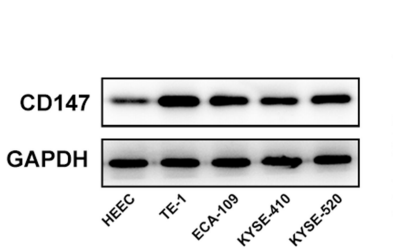

B

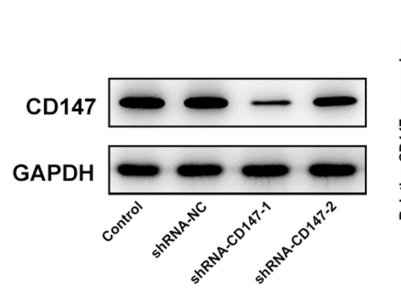

D

F
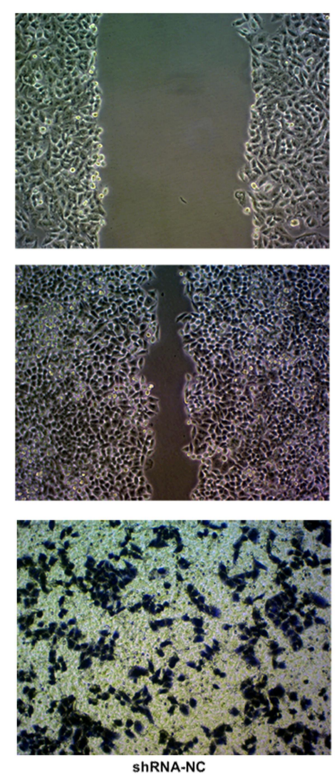

H
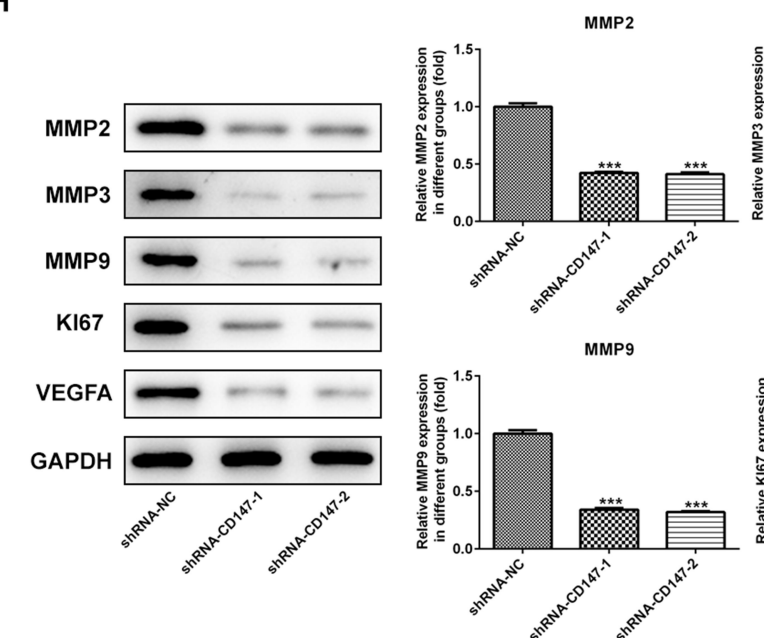
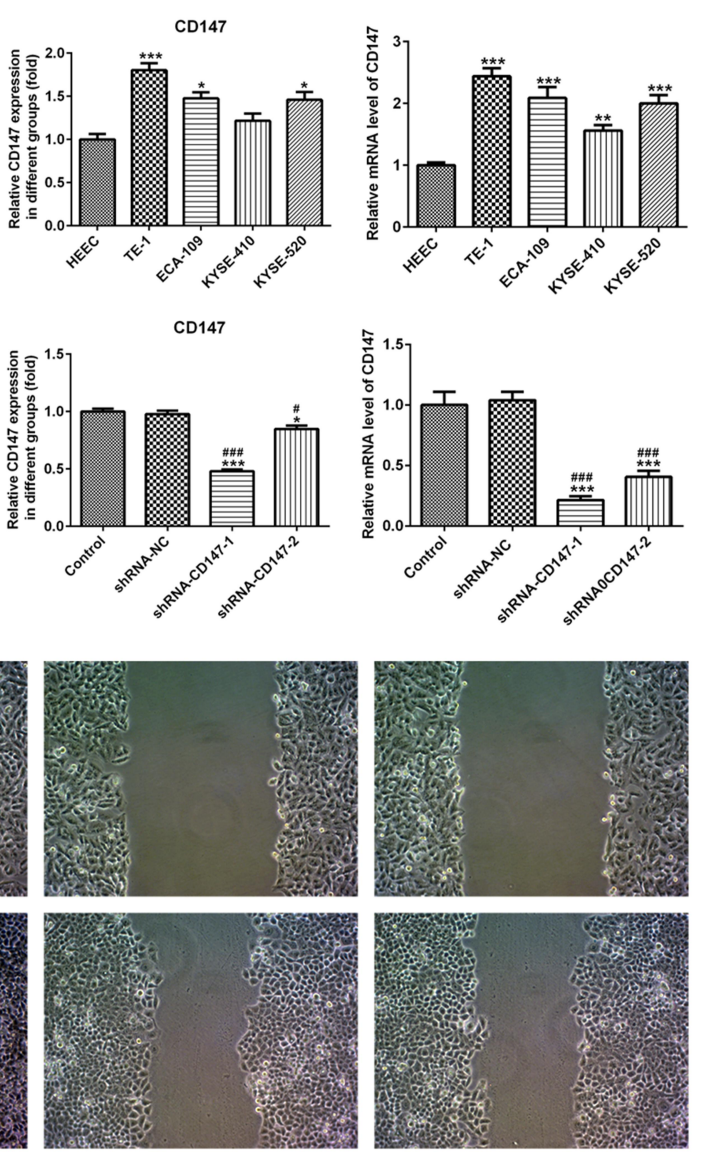

C
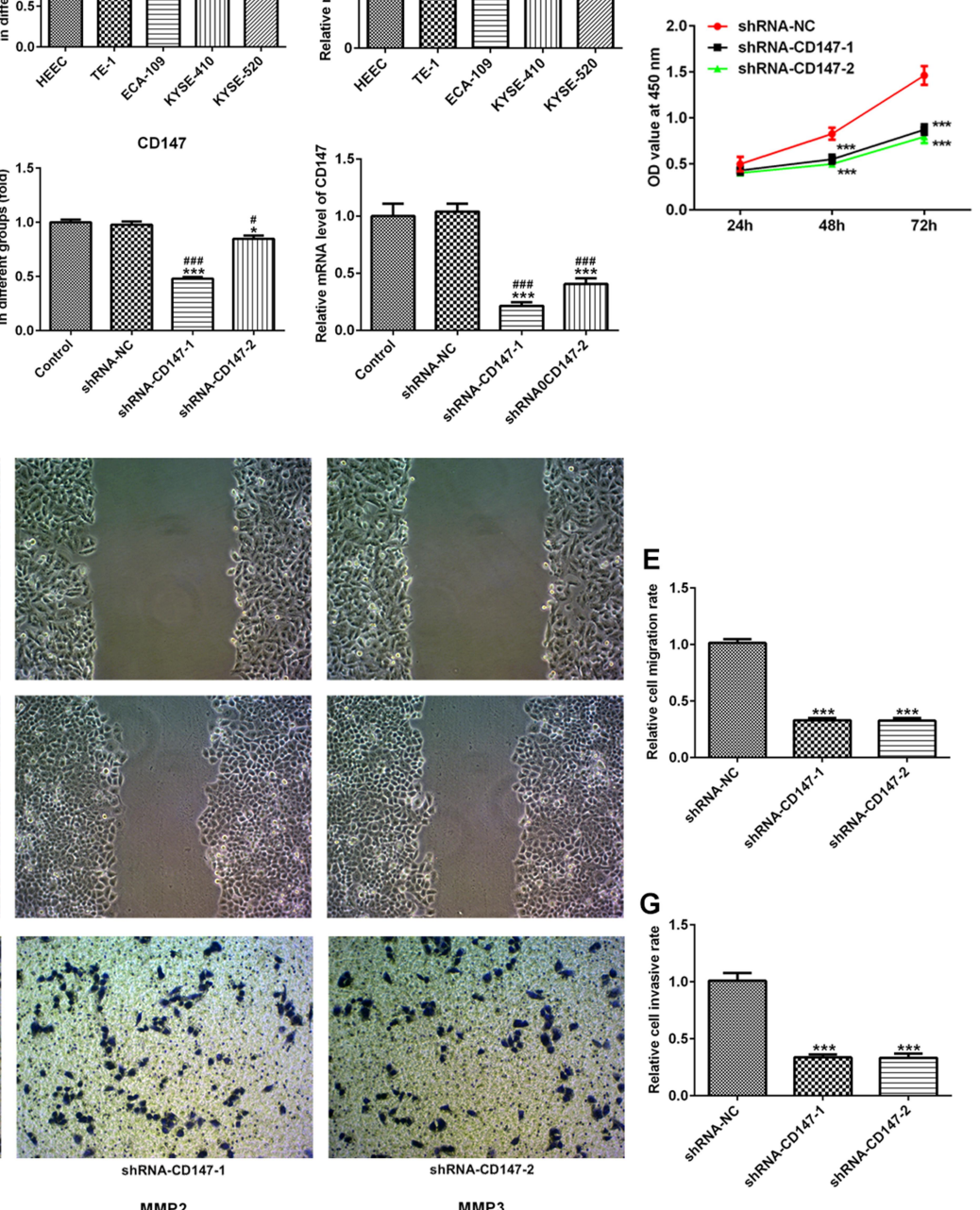
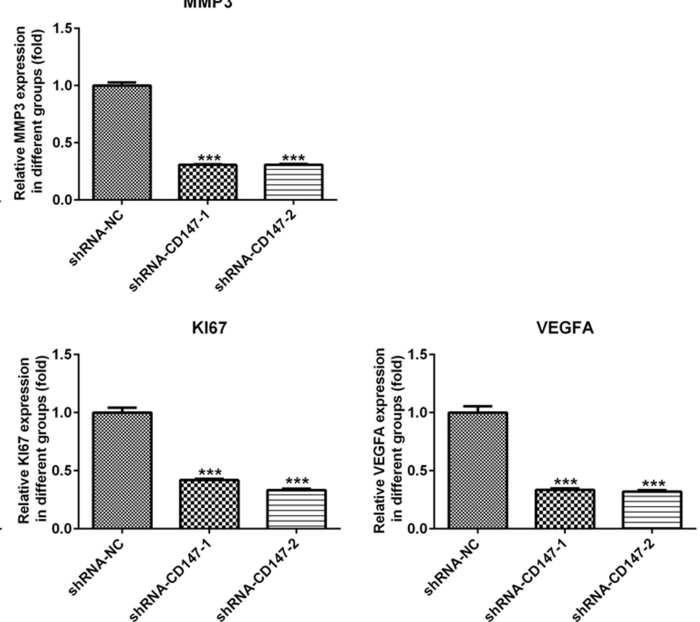

Figure 5 The role of CDI47 in ESCC. (A) The protein and mRNA expression levels of CDI47 were significantly increased in ESCC cells compared with HEEC cells. (B) The interfering plasmid of CDI47 was constructed and the interfering effect was detected by qRT-PCR and Western blot. (C) Knocking down CDI47 in TE-I cells restrained cell growth rate. (D-G) Transwell assays further confirmed that CDI47 knockdown blocked TE-I cell migration and invasion. (H) As determined by Western blot, Ki67, VEGFA, MMP2, MMP3, and MMP9 expression was decreased in CDI47 knockdown cells. $* P<0.05$, $* * P<0.0$ I, $* * * P<0.001$ vs control or HEEC or shRNA-NC. ${ }^{\# P} P<0.05,{ }^{\#} P<0.001$ vs shRNA-NC. 


\section{Interference with CDI47 Inhibited the Growth and Angiogenesis of ESCC Cells}

To confirm the in vitro effects of CD147 in vivo, we applied a ESCC xenograft model by subcutaneously transplanting shRNA-CD147-1 or shRNA-CD147-2 cells into nude mice randomly (shRNA-CD147-1 group and shRNA-CD147-2 group). Silencing of CD147 substantially repressed tumor expansion, along with a significant decrease in final tumor volume (Figure 6A and B) and weight (Figure 6C and D), compared with the control group. The MMP2, MMP3, MMP9, Ki67, CD43, and VEGFA protein expression was accordingly down-regulated (Figure 6E), indicating that interference with CD17 inhibited the growth of esophageal squamous cell cells. Furthermore, interference with CD17 could weaken the angiogenesis of ESCC cells (Figure 7A), with marked decrement of the mRNA and protein expression of VEGF and VEGFR in HUVEC cells (Figure 7B). Furthermore, compared with the control group, HUVEC numbers in the filtration membrane of the experimental group were lowered, and interference with CD147 had an inhibitory effect of the migration of endothelial cells (Figure 7C).

PAB exerted antitumor effects following CD147 overexpression.
A

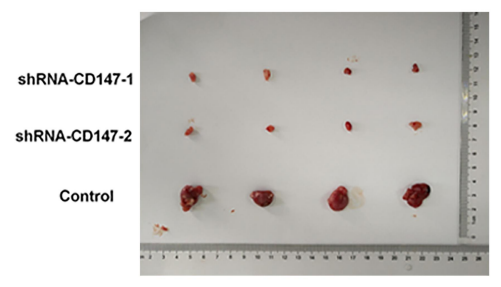

B

E

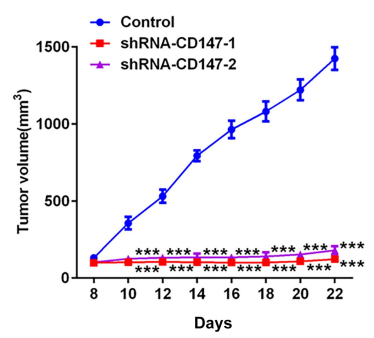

MMP2

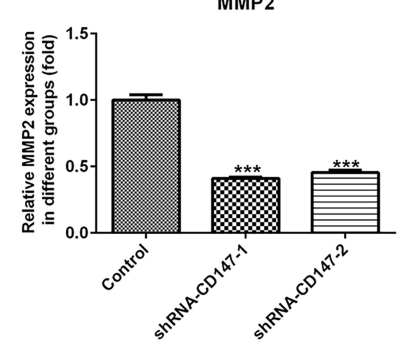

KI67

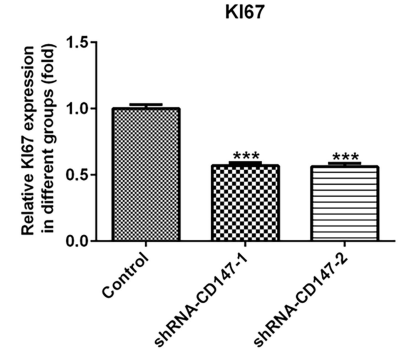

C
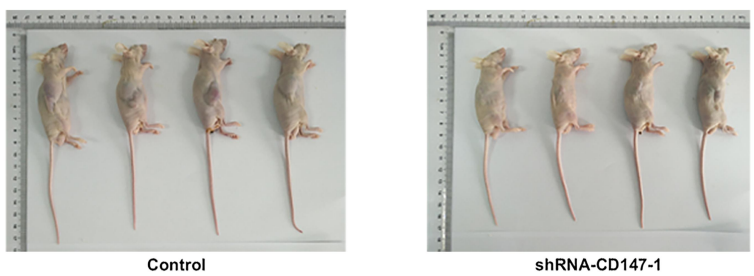

D
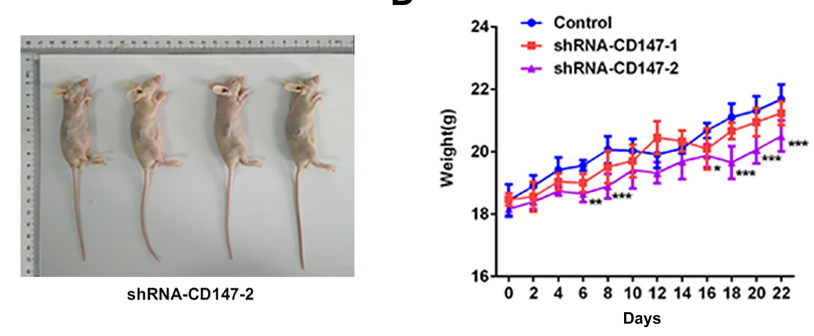

MMP3
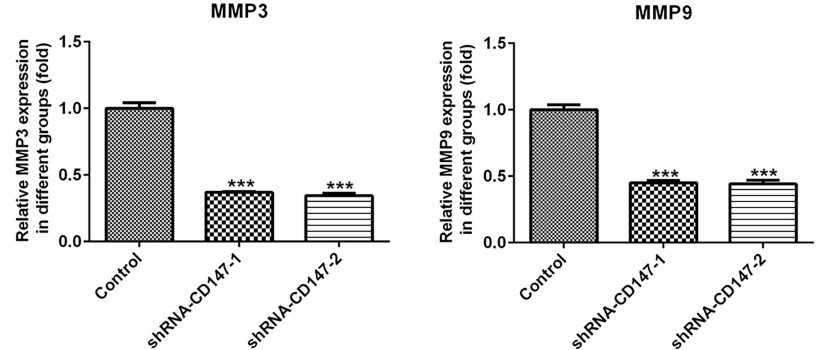

CD34

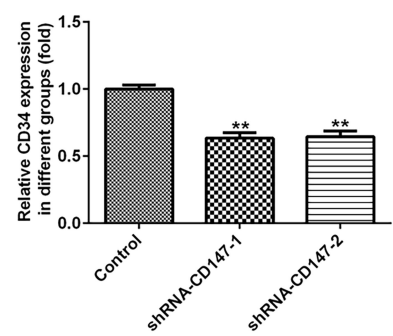

VEGFA

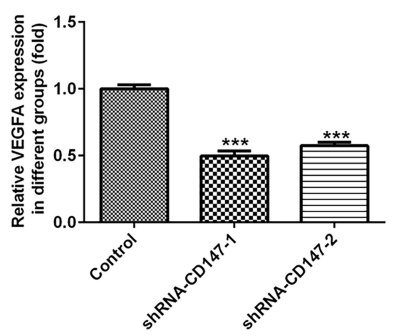

Figure 6 Interference with CDI7 inhibited the growth of ESCC. CDI47 inhibition substantially repressed tumor expansion, with an obvious decrease in final tumor volume (A-B) and weight (C-D) compared with the control group. (E) The relative MMP2, MMP3, MMP9, Ki67, CD43, and VEGFA protein expression was down-regulated. $* P<0.05, * * P<0.01$, $* * * P<0.001$ vs control. 
A

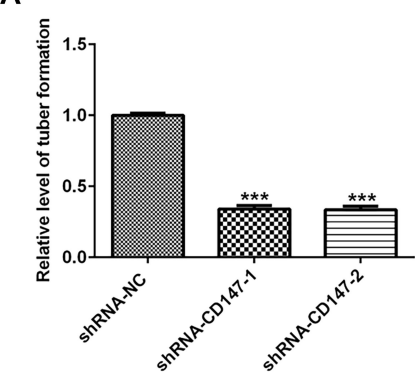

C

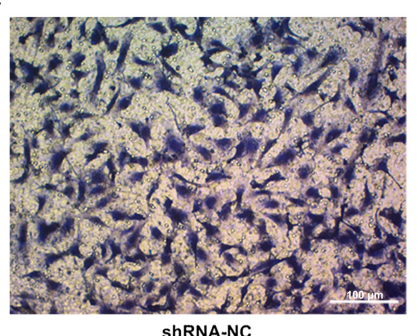

B
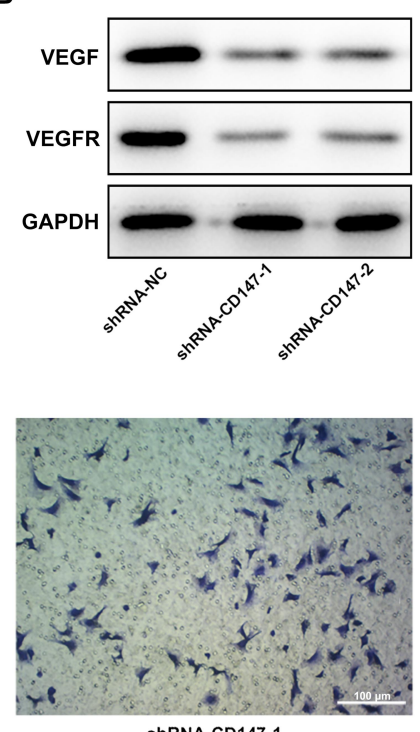

ShRNA-CD147-1
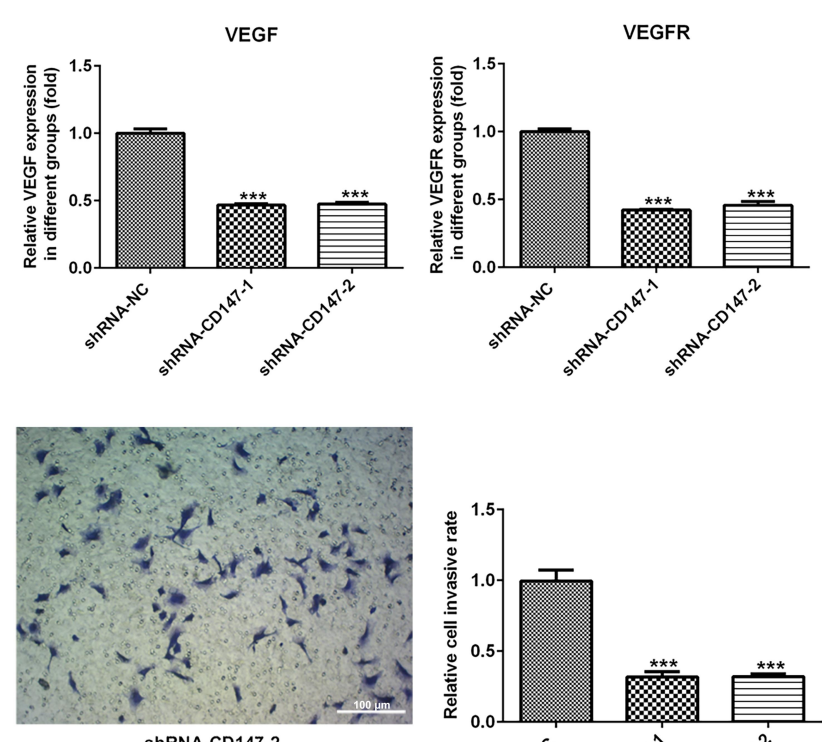

ShRNA-CD147-2

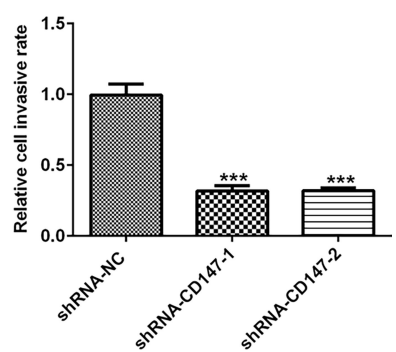

Figure 7 Interference with CDI7 inhibited angiogenesis of ESCC cells. (A) Interference with CDI7 markedly inhibited the angiogenesis of ESCC cells and decreased mRNA and protein expression of VEGF and VEGFR in HUVEC cells (B). Compared with the control group, reduced numbers of HUVEC in the filtration membrane of the experimental group were observed, and interference with CDI47 caused inhibition on the migration of endothelial cells (C). $* * * P<0.00 \mathrm{I}$ vs shRNA-NC.

Subsequently, the CD147 overexpression vector was transfected into TE-1 cells to determine whether CD147 served a role in the effects of PAB on cell proliferation, migration, and angiogenesis. The transfection efficacy of CD147 (Oe-CD147) in TE-1 cells was determined using RTqPCR and Western blot (Figure 8A). The expression level of CD147 in vivo and in vitro was detected by Western blot analysis, which showed obvious reduction under exposure to increasing concentration of PAB (Figure 8C-D). The transfection of Oe-CD147 reversed the suppressive effects of $\mathrm{PAB}$ on cell proliferation (Figure 8B) and migration (Figure 8EI). Taken together, these results suggested that $\mathrm{PAB}$ exerted antitumor effects following CD147 overexpression.

\section{Discussion}

Previous studies have shown that PAB has a strong cytotoxic effect on lung cancer, gastric cancer, liver cancer, prostate cancer, cervical cancer, and many other tumor cells, ${ }^{24-27}$ but the specific mechanism of its antitumor effects on ESCC is unclear, which may include inhibition of cell proliferation, cell cycle arrest, apoptosis induction, as well as repression of cell invasion and metastasis, etc. Recently, new progress about Hibiscus acid has been made in the study of antitumor mechanism of peracetic acid, such as induced autophagy of tumor cells, iron death, chemotherapy, and radiosensitization. Previous researches have reported that PAB is an anti-tubulin agent, which can induce cell cycle arrest of tumor cells by inhibiting the aggregation of tubulin. ${ }^{28}$ Yu et al ${ }^{29,30}$ found that PAB inhibits the growth of SW579 cells by interfering with $\alpha$-tubulin polymerization and promoting cell cycle arrest. The results of Wen et $\mathrm{al}^{31}$ showed that Hibiscus acid could inhibit the proliferation and mitosis of colorectal cancer cells. PAB can promote the apoptosis of many tumor cells, including hepatocarcinoma, lung cancer, breast cancer, melanoma, and rectal cancer. Guan et $\mathrm{al}^{10}$ discovered that Hibiscus acid could effectively inhibit Wnt signal and PAX2 expression, increase Bcl-2-related X protein (Bax) expression level, and induce HeLa cell apoptosis. In addition, Choi et $\mathrm{al}^{9}$ reported that Hibiscus acid promotes the apoptosis of hn22 cells by increasing the expression level of Caspase- 8 and activating the exogenous apoptosis pathway mediated by death receptor 5 (DR5). In this study, we unveiled that PAB inhibited cell proliferation, invasion, and migration, but activated apoptosis of esophageal squamous carcinoma cell line TE-1. We established in vivo? ESCC-bearing mice and found out that $\mathrm{PAB}$ could restrict the tumor growth in vivo. The antitumor effects of PAB were verified by in vivo and in vitro experiments.

CD147 mainly exists in the genital tract, eyes, brain, and muscles. In malignant tumors, the CD147 level is often overexpressed. Overexpression of CD147 is related to 
A

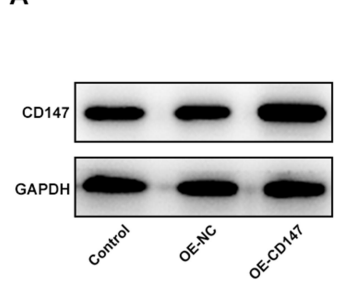

C

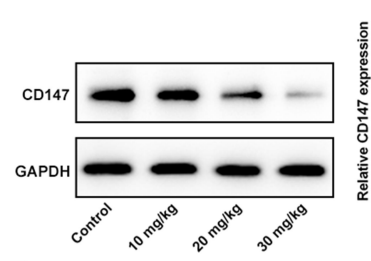

E
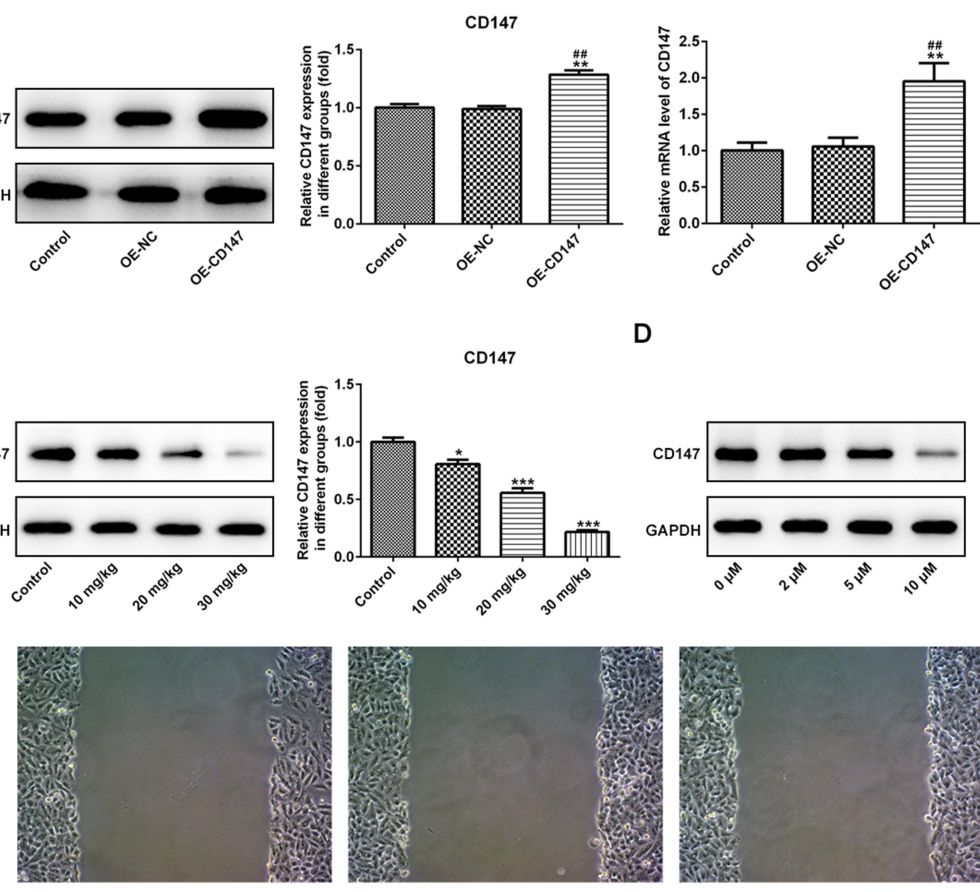

D

CD147
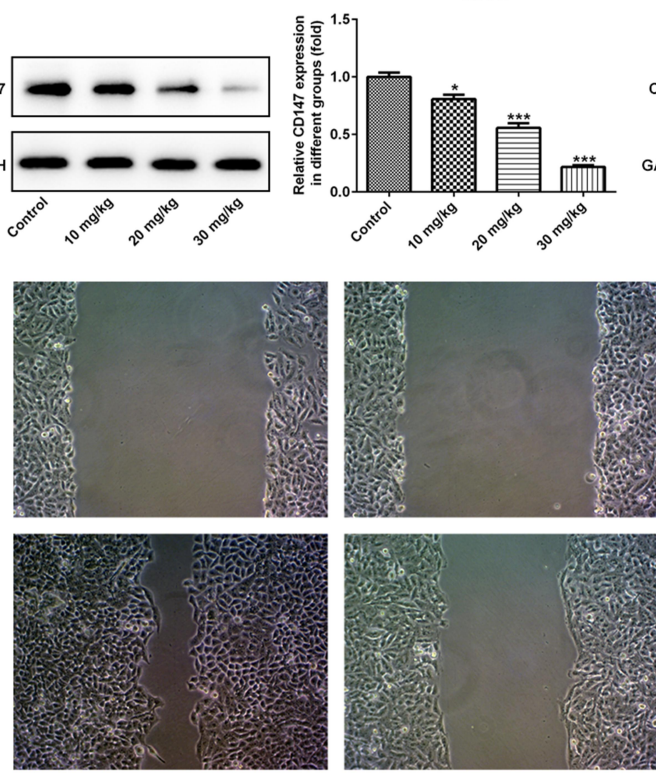

G
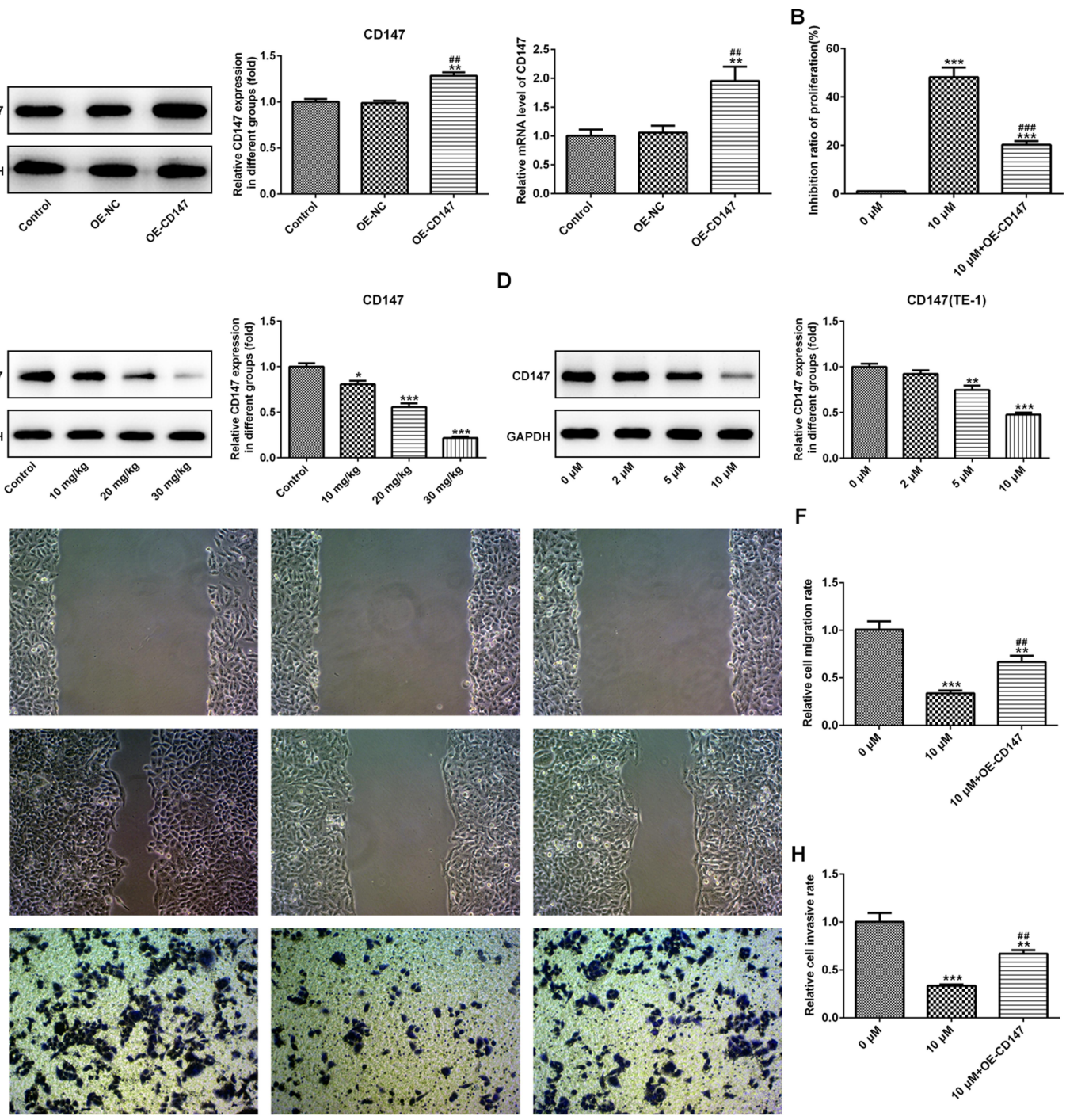

F
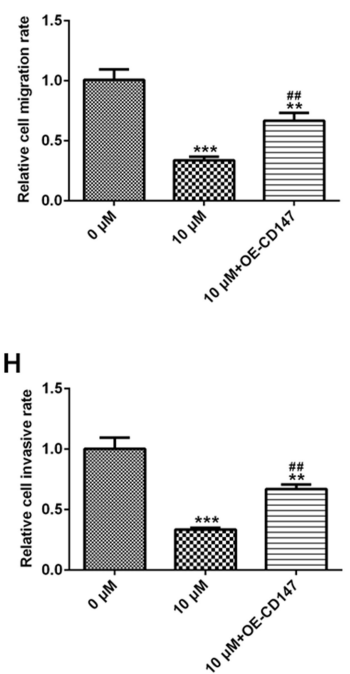

I
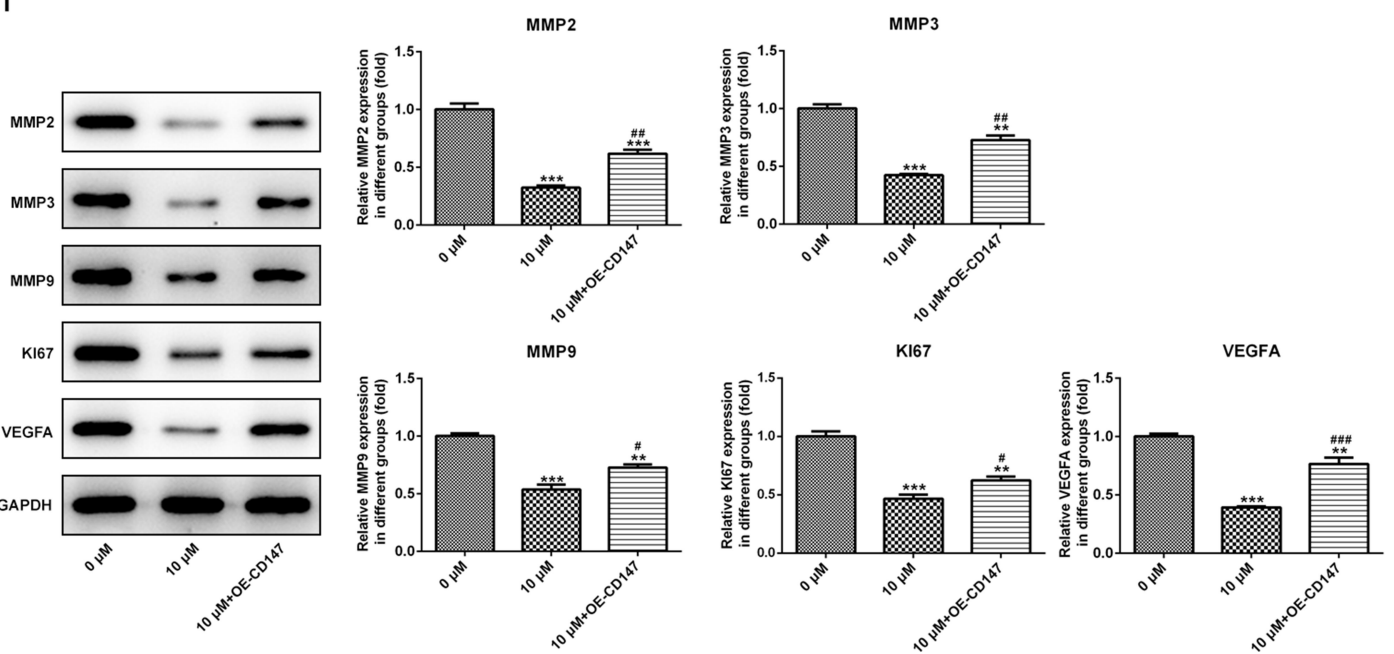

Figure 8 PAB possessed antitumor effects following CDI47 overexpression. The transfection efficacy of CDI47 (Oe-CDI47) in TE-I cells was determined using RT-qPCR and Western blot (A). The expression levels of CDI 47 in vivo and in vitro were detected by Western blot analysis. The expression of CDI47 decreased with the increasing of PAB concentration (C-D). The transfection of Oe-CDI47 abolished the effects of PAB on cell proliferation (B) and migration $(E-I)$. $* P<0.05$, **P<0.0I, ****P<0.00I vs control or $0 \mu \mathrm{M}$. ${ }^{\# P<0.05, ~}{ }^{\# P} P 0.01,{ }^{\#} P<0.001$ vs $\mathrm{OE}-\mathrm{CDI} 147$ or $10 \mu \mathrm{M}$. 
tumor progression and prognosis. High expression of CD147 usually indicates poor prognosis in patients. Tian et $\mathrm{al}^{32}$ demonstrated that CD147 is highly expressed in astrocytoma. Liu et $\mathrm{al}^{33}$ proved that CD147 is a predictor of poor prognosis in breast cancer patients. Ju et $\mathrm{al}^{34}$ found that CD147 is overexpressed in more than half of primary cervical cancers. Besides, Nakamura et $\mathrm{al}^{35}$ reported that CD147 is increased in endometrial cancer tissues. Similarly, high expression of CD147 is a poor prognostic factor in endometrial cancer patients. Zhao et $\mathrm{al}^{36}$ showed that the CD147 mRNA and protein levels in ovarian borderline tumors and epithelial cancer tissues were higher than those in benign ovarian tumors and normal tissues, and CD147 expression was positively correlated with tumor stage, dedifferentiation, and Ki-67 expression. The cumulative survival time and the relapse-free survival time of patients with high CD147 expression is shorter. From the above studies, we can see that CD147 is a molecule related to the degree of malignancies. In this study, we uncovered that CD147 expression in esophageal squamous cancer cells was increased, and the interference of CD147 can repress the proliferation and migration, restrain the growth of the esophageal squamous cancer cells in the body, and also inhibit angiogenesis of esophageal squamous cancer cells. Using chemical proteomics technology, PAB was revealed to directly target CD147, thus giving play to the role of anticancer. ${ }^{16}$ Currently, it was discovered that PAB inhibited the expression of CD147 in vivo and in vitro, and overexpression of CD147 restored the expression of MMP2, 3, and 9. Additionally, overexpression of CD147 neutralized the suppression of $\mathrm{PAB}$ on proliferation, invasion, migration, and angiogenesis of ESCC cells. In this study, we found that the expression of CD147 in ESCC cell lines was increased, and interference with CD147 could hamper the proliferation, invasion, and migration in vitro, inhibit the tumor growth in vivo, and impede angiogenesis.

Angiogenesis during tumorigenesis leads to aggressive and poor prognosis of ESCC. New blood vessels expand to provide oxygen and nutrients to proliferating tumor cells and also act as conduits for migration. Thus, understanding the molecular mechanisms that contribute to angiogenesis and anti-apoptosis may be beneficial for determining the biological basis of ESCC and improving its treatment. Angiogenesis refers to the process in which new capillaries germinate or divide from the original vessels through the activation, proliferation, migration, and channelization of endothelial cells. Growth of blood vessels is necessary for tumor growth and metastasis as blood vessels provide nutrients to tumor cells and remove waste from tumor cells. $^{37}$ In this work, PAB repressed the angiogenesis of HUVEC and interference with CD17 inhibited the growth and angiogenesis of ESCC cells. VEGF and VEGFR2mediated signal transduction and angiogenesis play a vital role in the pathogenesis of gastric cancer. ${ }^{38,39}$ PAB-induced anti-metastasis effect can also be attributed to its inhibitory effects on ECM processing and angiogenesis, which was manifested through decreased expression of MMP9, HIF-1, VEGF, and VEGFR2, and increased expression of E-cadherin and Ezrin. In addition, VEGF has been reported to induce the expression of anti-apoptotic protein Bcl-2 and down-regulate the expression of pro-apoptotic proteins Bax and caspase-3, consistent with this study.

\section{Conclusion}

In conclusion, $\mathrm{PAB}$ inhibited the proliferation and invasion properties of ESCC cells in vitro and promoted cell apoptosis in ESCC cells. We observed that Ki67, VEGFA, MMP2, MMP3, and MMP9 expression was dramatically decreased in CD147 knockdown cells, indicating the potential mechanism of CD147 to modulate the cell migration and invasion. Besides, interference with CD147 inhibited the growth and angiogenesis of ESCC cells. PAB exerted antitumor effects following CD147 overexpression, indicating that the PAB may be a novel therapeutic target for the treatment of ESCC. These results can be used for further study of the application of PAB as a pharmacological agent.

\section{Funding}

Chongqing Science and Technology Bureau Technology Innovation and Application Development Project. (Grant number: cstc2019jscx-msxmX0283).

\section{Disclosure}

The authors disclose no potential conflicts of interest.

\section{References}

1. Chen W, Zheng R, Baade PD, et al. Cancer statistics in China, 2015. CA Cancer J Clin. 2016;66(2):115-132. doi:10.3322/caac.21338

2. Rustgi A, El-Serag HB. Esophageal carcinoma. $N$ Engl J Med. 2015;372(15):1472-1473

3. Murta CB, Antunes AA, Dall'Oglio MF, Mosconi A, Leite KR, Srougi M. Analysis of the clinicopathological characteristics of patients with upper urinary tract transitional cell carcinoma. Clinics. 2008;63(2):223-228.

4. Dutton SJ, Ferry DR, Blazeby JM, et al. Gefitinib for oesophageal cancer progressing after chemotherapy (COG): a Phase 3, multicentre, double-blind, placebo-controlled randomised trial. Lancet Oncol. 2014;15(8):894-904. 
5. Ando N, Ozawa S, Kitagawa Y, Shinozawa Y, Kitajima M. Improvement in the results of surgical treatment of advanced squamous esophageal carcinoma during 15 consecutive years. Ann Surg. 2000;232(2):225-232.

6. Li T, Wang W, Li YX, et al. Pseudolaric acid B attenuates atherosclerosis progression and inflammation by suppressing PPARgamma-mediated NF-kappaB activation. Int Immunopharmacol. 2018;59:76-85.

7. Wang Z, Ding Y, Wang X, et al. Pseudolaric acid B triggers ferroptosis in glioma cells via activation of Nox4 and inhibition of $\mathrm{xCT}$. Cancer Lett. 2018;428:21-33.

8. Li S, Guo L. [Pseudolaric acid B induces G2/M arrest and inhibits invasion and migration in HepG2 hepatoma cells]. Xi Bao Yu Fen $\mathrm{Zi}$ Mian Yi Xue Za Zhi. 2018;34(1):59-64. Chinese.

9. Choi SJ, Ahn $\mathrm{CH}$, Yang IH, et al. Pseudolaric Acid B Induces Growth Inhibition and Caspase-Dependent Apoptosis on Head and Neck Cancer Cell lines through Death Receptor 5. Molecules. 2019;24:20.

10. Guan D, Li C, Lv X, Yang Y. Pseudolaric acid B inhibits PAX2 expression through Wnt signaling and induces BAX expression, therefore promoting apoptosis in $\mathrm{HeLa}$ cervical cancer cells. J Gynecol Oncol. 2019;30(5):e77. doi:10.3802/jgo.2019.30.e77

11. Evidence-Based C, Alternative M. Expression of Concern on "Pseudolaric Acid B Induces Caspase-Dependent and CaspaseIndependent Apoptosis in U87 Glioblastoma Cells". Evid Based Complement Alternat Med. 2019;2019:4959838.

12. Zhang H, Li J-C, Luo H, Zhao L, Zhang Z-D, Shen X-F. Pseudolaric acid $\mathrm{B}$ exhibits anti-cancer activity on human hepatocellular carcinoma through inhibition of multiple carcinogenic signaling pathways. Phytomedicine. 2019;59:152759. doi:10.1016/j.phymed.2018.11.019

13. Pantho AF, Price M, Ashraf AZ, et al. Synthetic Receptors Induce Anti Angiogenic and Stress Signaling on Human First Trimester Cytotrophoblast Cells. Int J Environ Res Public Health. 2017;14 (5):5. doi:10.3390/ijerph14050517

14. Tong Y-G, Zhang X-W, Geng M-Y, et al. Pseudolarix acid B, a new tubulin-binding agent, inhibits angiogenesis by interacting with a novel binding site on tubulin. Mol Pharmacol. 2006;69 (4):1226-1233. doi:10.1124/mol.105.020537

15. Li M-H, et al. Pseudolaric Acid B Inhibits Angiogenesis and Reduces Hypoxia-Inducible Factor 1 by Promoting Proteasome-Mediated Degradation. Clin Cancer Res. 2004;10(24):8266-8274. doi:10.1158/1078-0432.CCR-04-0951

16. Zhou Y, Di Z, Li X, et al. Chemical proteomics reveal CD147 as a functional target of pseudolaric acid B in human cancer cells. Chem Commun (Camb). 2017;53(62):8671-8674. doi:10.1039/ C7CC04345G

17. Egawa N, Koshikawa N, Tomari T, Nabeshima K, Isobe T, Seiki M. Membrane type 1 matrix metalloproteinase (MT1-MMP/MMP-14) cleaves and releases a $22-\mathrm{kDa}$ extracellular matrix metalloproteinase inducer (EMMPRIN) fragment from tumor cells. J Biol Chem. 2006;281(49):37576-37585. doi:10.1074/jbc.M606993200

18. Xu T, Zhou M, Peng L, et al. Upregulation of CD147 promotes cell invasion, epithelial-to-mesenchymal transition and activates MAPK/ ERK signaling pathway in colorectal cancer. Int J Clin Exp Pathol. 2014;7(11):7432-7441.

19. Wu J, Ru NY, Zhang Y, et al. HAb18G/CD147 promotes epithelial-mesenchymal transition through TGF-beta signaling and is transcriptionally regulated by Slug. Oncogene. 2011;30 (43):4410-4427.

20. Yang S, Qi F, Tang C, et al. CD147 promotes the proliferation, invasiveness, migration and angiogenesis of human lung carcinoma cells. Oncol Lett. 2017;13(2):898-904.
21. Ishibashi Y, Matsumoto T, Niwa M, et al. CD147 and matrix metalloproteinase-2 protein expression as significant prognostic factors in esophageal squamous cell carcinoma. Cancer. 2004;101 (9): 1994-2000.

22. Cheng MF, Tzao C, Tsai WC, et al. Expression of EMMPRIN and matriptase in esophageal squamous cell carcinoma: correlation with clinicopathological parameters. Dis Esophagus. 2006;19(6):482-486.

23. Zhu S, Li Y, Mi L, et al. Clinical impact of HAb18G/CD147 expression in esophageal squamous cell carcinoma. Dig Dis Sci. 2011;56 (12):3569-3576.

24. Yao GD, Yang J, Li XX, et al. Blocking the utilization of glucose induces the switch from senescence to apoptosis in pseudolaric acid B-treated human lung cancer cells in vitro. Acta Pharmacol Sin. 2017;38(10):1401-1411.

25. Sun Q, Li Y. The inhibitory effect of pseudolaric acid B on gastric cancer and multidrug resistance via Cox-2/PKC-alpha/P-gp pathway. PLoS One. 2014;9(9):e107830.

26. Zhao D, Lin F, Wu X, et al. Pseudolaric acid B induces apoptosis via proteasome-mediated $\mathrm{Bcl}-2$ degradation in hormone-refractory prostate cancer DU145 cells. Toxicol in Vitro. 2012;26(4):595-602.

27. Li M, Hong L. Pseudolaric acid B exerts antitumor activity via suppression of the Akt signaling pathway in HeLa cervical cancer cells. Mol Med Rep. 2015;12(2):2021-2026.

28. Khan M, Zheng B, Yi F, et al. Pseudolaric Acid B induces caspase-dependent and caspase-independent apoptosis in u87 glioblastoma cells. Evid Based Complement Alternat Med. 2012;2012:957568.

29. Li X, Zhao X, Song W, et al. Pseudolaric Acid B Inhibits Proliferation, Invasion and Epithelial-to-Mesenchymal Transition in Human Pancreatic Cancer Cell. Yonsei Med J. 2018;59(1):20-27.

30. Yu J, Ren P, Zhong T, et al. Pseudolaric acid B inhibits proliferation in SW579 human thyroid squamous cell carcinoma. Mol Med Rep. 2015;12(5):7195-7202.

31. Wen C, Chen J, Zhang D, et al. Pseudolaric acid B induces mitotic arrest and apoptosis in both 5-fluorouracil-sensitive and -resistant colorectal cancer cells. Cancer Lett. 2016;383(2):295-308.

32. Tian L, Zhang Y, Chen Y, Cai M, Dong H, Xiong L. EMMPRIN is an independent negative prognostic factor for patients with astrocytic glioma. PLoS One. 2013;8(3):e58069.

33. Liu F, Cui L, Zhang Y, et al. Expression of HAb18G is associated with tumor progression and prognosis of breast carcinoma. Breast Cancer Res Treat. 2010;124(3):677-688.

34. Ju XZ, Yang JM, Zhou XY, Li ZT, Wu XH. EMMPRIN expression as a prognostic factor in radiotherapy of cervical cancer. Clin Cancer Res. 2008;14(2):494-501.

35. Nakamura K, Kodama J, Hongo A, Hiramatsu Y. Role of emmprin in endometrial cancer. BMC Cancer. 2012;12:191.

36. Zhao Y, Chen S, Gou WF, et al. The role of EMMPRIN expression in ovarian epithelial carcinomas. Cell Cycle. 2013;12(17):2899-2913.

37. Bisacchi D, Benelli R, Vanzetto C, Ferrari N, Tosetti F, Albini A. Anti-angiogenesis and angioprevention: mechanisms, problems and perspectives. Cancer Detect Prev. 2003;27(3):229-238.

38. Lian L, Li XL, Xu MD, et al. VEGFR2 promotes tumorigenesis and metastasis in a pro-angiogenic-independent way in gastric cancer. BMC Cancer. 2019;19(1):183.

39. Sorokin M, Poddubskaya E, Baranova M, et al. RNA sequencing profiles and diagnostic signatures linked with response to ramucirumab in gastric cancer. Cold Spring Harb Mol Case Stud. 2020;6:2. 


\section{Publish your work in this journal}

Drug Design, Development and Therapy is an international, peerreviewed open-access journal that spans the spectrum of drug design and development through to clinical applications. Clinical outcomes, patient safety, and programs for the development and effective, safe, and sustained use of medicines are a feature of the journal, which has also

been accepted for indexing on PubMed Central. The manuscript management system is completely online and includes a very quick and fair peer-review system, which is all easy to use. Visit http://www. dovepress.com/testimonials.php to read real quotes from published authors.

Submit your manuscript here: https://www.dovepress.com/drug-design-development-and-therapy-journal 